\title{
REGISTRO DA PRESSÃO INTRACRANIANA
}

\author{
Paulo andrade de Mello * \\ Carlos Telles ** \\ Márcio PaLlis HoRTa **
}

Desde os trabalhos de Lundberg $^{1}$ que, em 1960, relatou o registro da pressão intraventricular em pacientes com traumatismos cranioencefálicos, a atenção de numerosos pesquisadores tem sido voltada para o assunto. E antiga a aspiração dos neurocirurgiōes por métodos que ofereçam, com segurança, a idéia da pressão nos diferentes compartimentos intracranianos. Tais métodos, quando estabelecidos na rotina médica, oferecerão parâmetros importantes para orientar o tratamento clínico ou mesmo determinar o momento indicado para investigaçōes especializadas no tratamento cirúrgico. Os trabalhos de Lundberg além de levantar o problema e criar uma metodologia própria, estimularam os autores a procurar novos métodos que pudessem guardar íntima relação com o primeiro ao mesmo tempo que evitassem os inconvenientes de puncionar o cérebro.

Nesta linha de trabalho sucederam-se comunicações que parecem ter criado as condições ideais para a primeira troca de impressões em escala internacional como ocorreu no Simpósio de Hannover, em julho de $1972^{2}$. Com a apresentação de 60 trabalhos todos acompanhados de discussão ativa o Simpósio reuniu os principais interessados no registro da pressão intracraniana.

As seguintes recomendações emergiram do Simpósio de Hannover e, por certo, deverão nortear as pesquisas sobre pressão intracraniana nos próximos anos: 1) o registro da pressão intracraniana é possivelmente o meio mais seguro para orientar o tratamento de pacientes vitimas de variadas condições neurológicas nas quais a pressão intracraniana tende a aumentar; 2) a metodologia para registro da pressão intracraniana inclui registros no compartimento liquórico, ventricular e extraventricular (subdural e epidural); 3) o método de registro intraventricular até o momento é o mais eficiente. Foi considerada, porém, pela maioria dos autores, a necessidade de aperfeiçoar métodos mais simples e com menores riscos de complicações. Neste sentido deve ser realçada a contribuição trazida pelos participantes do Simpósio que abordaram de forma ampla as diferentes formas de registro da pressão bem como a sua correlação com diversos fatores.

Trabalho da Unidade de Neurocirurgia, $1^{*}$ Hospital Distrital de Brasilia: Chefe da Unidade de Neurocirurgia; ** Neurocirurgião. 


\section{MATERIAL E MẼTODOS}

$\mathrm{Na}$ Unidade de Neurocirurgia do $1^{0}$ Hospital Distrital de Brasília, iniciamos uma série de experiências, visando ao desenvolvimento de técnicas de registro da pressāo intracraniana.

Usando a técnica de balão extradural, assinalada por Brock e col. 3, uma sérje de 11 gatos foi submetida a narcose com barbitúricos, com medida sistemática da pressão intracraniana até a embolizaçāo maciça dos principais vasos cerebrais. Cada animal foi contido no aparelho tipo Horsley-Clark do Departamento de Neurofisiologia da UnB (Fig. 1) e para o registro da pressão utilizou-se um transdutor de pressão HP $1280 \mathrm{C}$ adaptado a um conjunto de amplificador e inscritor térmico de dois canais. A experiencia foi monitorada mediante um osciloscópio de dois canais adaptado ao aparelho, sendo a pressão registrada até a morte do animal (Fig. 2 ).

A mesma técnica de registro foi utilizada em uma série de 3 pacientes com traumatismo cranioencefálico grave e sinais de descerebração. Os pacientes foram previamente submetidos à angiografia carotídea que não revelou presença de hematoma extradural ou subdural.

No primeiro paciente tentamos, sem sucesso, a técnica de fixação do balāo com cimento de dentista. Nas primeiras horas houve vazamento que prejudicou a observação. Desenvolvemos então uma nova técnica de fixação usando botōes de polietileno fixados à tábua externa por meio de parafusos (Fig. 3).

Caso 3 - Paciente vitima de atropelamento, em 28-3-1973 foi internada no P.S. do $1^{*}$ HDB inconsciente, sem reagir a qualquer estimulo. Foi admitida na Unidade de Terapia Intensiva e, 12 horas após, passou a apresentar rigidez de descerebração, inicialmente à esquerda e ulteriormente bilateral. Desde a admissão havia anisocoria com midríase fixa à direita. A angiografia carotídea havia excluido a presença de hematoma. A paciente permaneceu em coma, com sinais de descerebração até o óbito, ocorrido em 15-4-1973 (Fig. 4).

Recentemente nossa atenção tem sido voltada para o registro da pressão intraventricular em pacientes com manifestações de lesão do tronco cerebral.

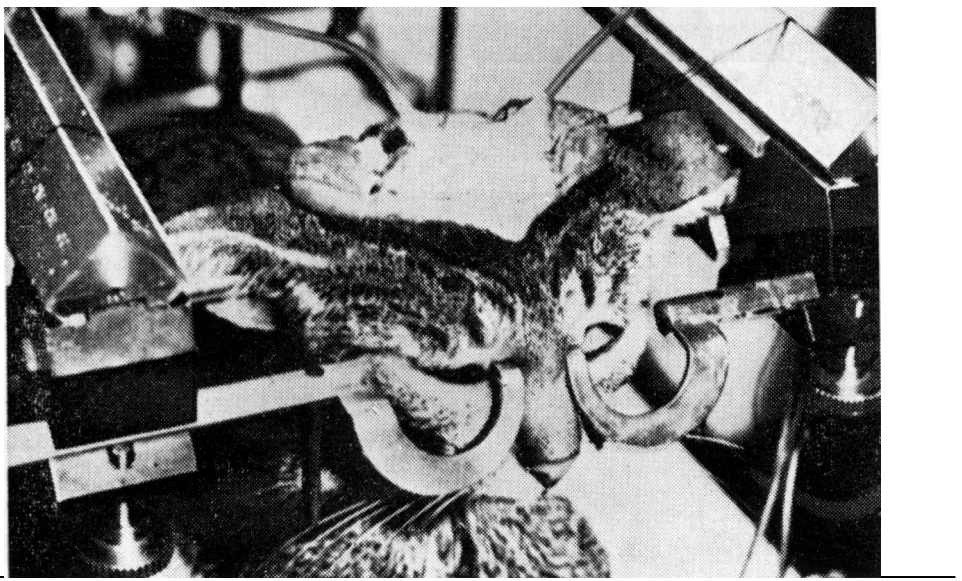

Fig. 1 - Animal fixado ao aparelho de estereotaxia tipo Horsley-Clark. Observem-se os balões medidores da pressão intracraniana fixados com cimento de dentista. 


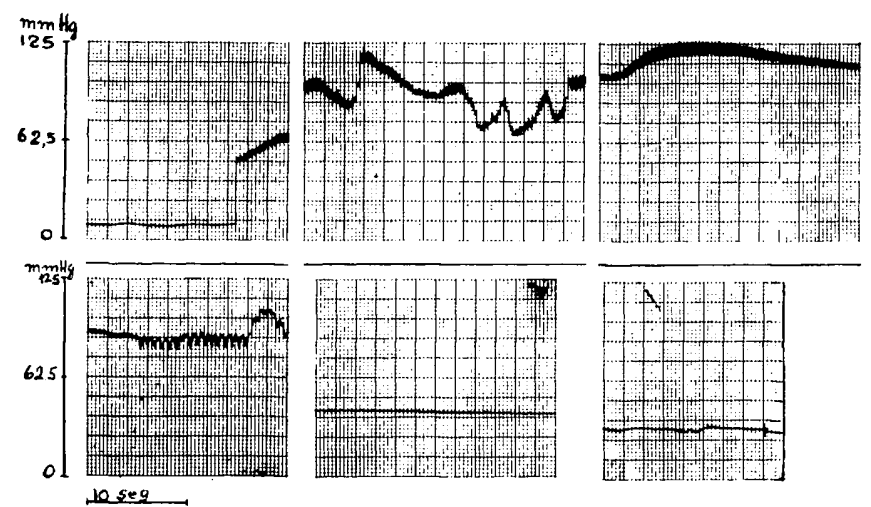

Fig. 2 - Registro da pressão extradural em um dos animais. A pressão inicial que se encontrava em torno de $60 \mathrm{~mm}$ de $\mathrm{Hg}$ atingiu um nivel máximo de $125 \mathrm{mmHg}$ após a embolização maciça $e$ foi progressivamente baixando até $\grave{a}$ morte do animal.

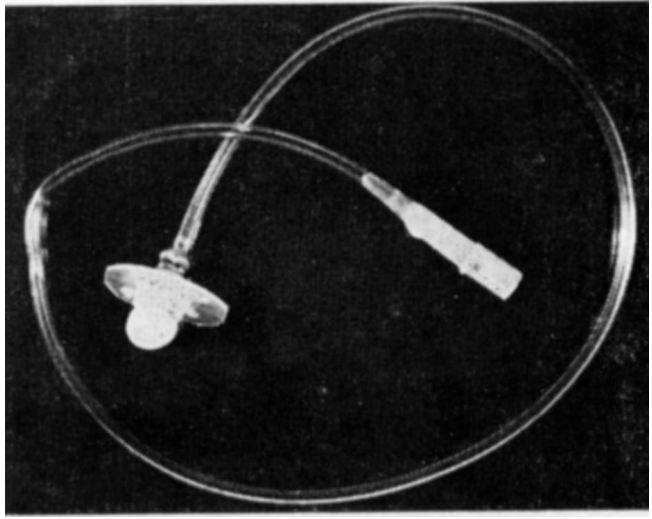
Fig. 3 - Balão para registro extradural da pressão intracraniana. Observem-se os
orifícios para fixação do mesmo à tábua externa do crânio com parafusos.

Uma série de 11 pacientes com traumatismo cranioencefálico e sinais de descerebração foi submetida à trepanação exploradora, seguida de inserção de uma cânula intraventricular.

o método é de fácil execucão e os resultados bastante seguros para orientar quanto ao momento adequado para introdução de medidas destinadas a combater a hipertensão (Fig. 5).

\section{COMENTÁRIOS}

Com a presente série, pretendeu-se desenvolver a técnica de registro da pressão intracraniana, a fim de utilizá-la em pacientes internados em Unidade de Terapia Intensiva. O número de casos é pequeno para conclusões, porém, 


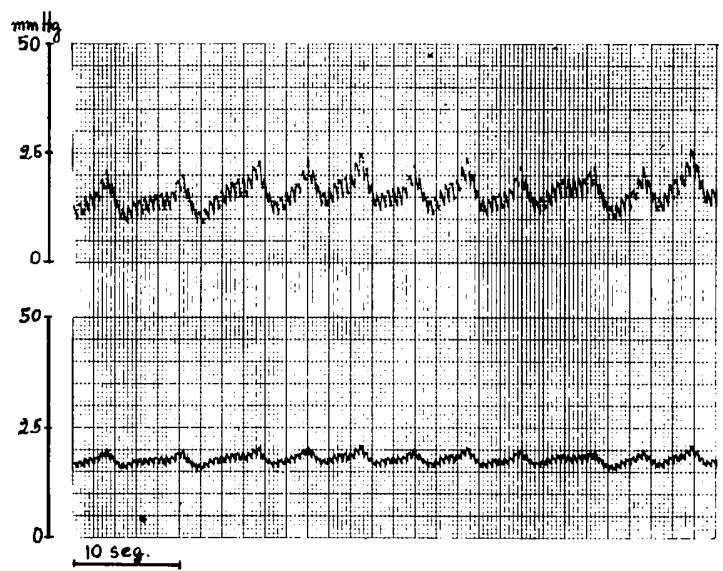

Fig. 4 - Caso 3. Registro contínuo da pressão intracraniana no homem através de balão extradural bilateral. As diferenças de pressão entre o lado direito (acima) e esquerä (abaixo) devem-se provavelmente a edema cerebral, maior no lado direito.
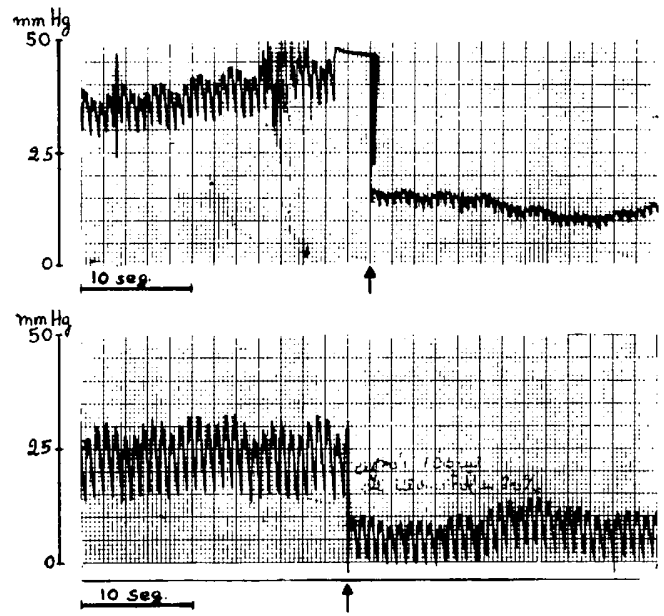

Fig. 5 - Registro contínuo da pressīo intraventricular no homem. No gráfico superior, a pressão caiu de 40 para $15 \mathrm{mmHg}$ após retirada de $3 \mathrm{ml}$ de liquor intraventricular. No gráfico inferior, a pressão caiu de 20 para $5 \mathrm{mmHg}$ após a administração de $100 \mathrm{ml}$ de manitol a $20 \%$.

é importante assinalar que obtivemos resultados idênticos àqueles registrados pela maioria dos autores que tratam do assunto.

Diferenças de pressões entre um lado e outro do crânio pođem estar relacionadas com alterações patológicas, o que em nosso terceiro caso correspondeu possivelmente ao edema cerebral. Nas condições atuais de trabalho a pressão intraventricular parece oferecer maior fidelidade nos registros, além de ser de fácil acesso. 
Com a integração do método na rotina de observação de pacientes graves, considerações poderão ser feitas, no futuro, sobre a ação de drogas no controle da pressão intracraniana.

\section{RESUMO}

Os autores apresentam uma revisão sobre a metodologia de registro da pressão intracraniana e suas aplicaçōes no homem. Consideraçōes são feitas sobre o registro experimental em animais submetidos à embolização cerebral aguda. São apresentados os resultados da pressão extradural e intraventricular em pacientes com manifestações de lesões do tronco cerebral.

\section{SUMMARY}

Continuous recording of intracranial pressure

A revision of the methodology for recording intracranial pressure and its use in man is made. Experience is presented with animal embolism followed by recording the extradural pressure. Preliminary report is made about the extradural and intraventricular pressure in patients with signs of involvement of the brain stem.

\section{REFERENCIAS}

1. LUNDBERG, N. - Continuous recording and control of ventricular fluid pressure in neurosurgical practice. Acta Psychiat Scand (Suppl. 149) 36:1-193, 1960.

2. BROCK, M. \& DIETZ, H. - Intracranial Pressure. Springer Verlag. BerlinHeidelberg-New York, 1972.

3. BROCK, M; BECK, J. \& MARKAKIS, E. - Intracranial pressure gradients associated with experimental cerebral embolism. Stroke 3:123, 1972.

Unidade de Neurocirurgia - $\mathbf{1}^{\circ}$ Hospital Distrital de Brasilia - 70000 Brasília, D.F. - Brasil. 